\title{
Responding to the deaf in disasters: establishing the need for systematic training for state-level emergency management agencies and community organizations
}

\author{
Alina Engelman ${ }^{1 *}$, Susan L Ivey ${ }^{1}$, Winston Tseng ${ }^{1}$, Donna Dahrouge ${ }^{1}$, Jim Brune $^{2}$ and Linda Neuhauser ${ }^{1}$
}

\begin{abstract}
Background: Deaf and hard-of-hearing (Deaf/HH) individuals have been underserved before and during emergencies. This paper will assess Deaf/HH related emergency preparedness training needs for state emergency management agencies and deaf-serving community-based organizations (CBOs).

Methods: Four approaches were used: 1) a literature review; 2) results from 50 key informant (KI) interviews from state and territorial-level emergency management and public health agencies; 3) results from $14 \mathrm{KI}$ interviews with deaf-serving CBOs in the San Francisco Bay Area; and 4) a pilot program evaluation of an emergency responder training serving the Deaf/HH in one urban community.

Results: Results from literature review and state and territorial level Kls indicate that there is a substantive gap in emergency preparedness training on serving Deaf/HH provided by state agencies. In addition, local Kl interviews with 14 deaf-serving CBOs found gaps in training within deaf-serving CBOs. These gaps have implications for preparing for and responding to all-hazards emergencies including weather-related or earthquake-related natural disasters, terrorist attacks, and nuclear-chemical disasters.

Conclusion: Emergency preparedness trainings specific to responding to or promoting preparedness of the Deaf/ $\mathrm{HH}$ is rare, even for state agency personnel, and frequently lack standardization, evaluation, or institutionalization in emergency management infrastructure. This has significant policy and research implications. Similarly, CBOs are not adequately trained to serve the needs of their constituents.
\end{abstract}

Keywords: All-hazards, Deaf, First responders, Emergency preparedness, Training

\section{Significance}

Almost no information exists in the peer-reviewed literature about the emergency preparedness training standards and current trainings provided for Deaf and hard-of-hearing (Deaf/HH) populations. However, recent national and international disasters that required humanitarian efforts illustrate the fact that Deaf and hard-of-hearing (Deaf/HH) individuals are often not only underserved, but also particularly vulnerable, in preparing for, responding to, and recovering from emergencies

\footnotetext{
* Correspondence: engelman@berkeley.edu

${ }^{1}$ Health Research for Action, School of Public Health, University of California, Berkeley, 2140 Shattuck Avenue, 10th Floor, Berkeley, CA 94704, USA Full list of author information is available at the end of the article
}

[1]. In the United States, according to a landmark 2004 report by Stout, "a failing grade" was given to U.S. public warning and emergency communications systems serving the Deaf/HH post-9/11 [1]. According to the Office of Homeland Security's 2006 Nationwide Plan Review of 2,800 state and local emergency operations plans (EOPs) and related documents which included interviews with over 1,000 public safety and homeland security officials across the US, the word Deaf appeared only 8 times in their entire report $[2,3]$.

However, FEMA's Office of Disability Integration and Coordination's list of key concepts provide a starting point at the national level to provide guidance for ensuring people with disabilities are included in, and not left

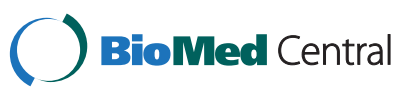


out of, the emergency management infrastructure across the US. These concepts include self-determination, no "One-Size-Fits-All," equal opportunity, inclusion, integration, physical access, equal access, effective communication, and program modifications [4].

\section{Background}

\section{The Deaf/HH population}

There are 48 million Deaf, deaf-blind, and hard-of-hearing $(\mathrm{HH})$ people living in the United States [5]. Communication needs vary depending on level of hearing loss and cultural orientation. The diverse communication modalities in this population include American Sign Language (ASL), Signed Exact English (SEE), Pidgin Signed English (PSE), Cued Speech, lip-reading and spoken English. Recent research indicates that this population faces serious health disparities due to communication barriers and low literacy rates, including a higher risk for obesity, depression, and interpersonal violence. In particular, these communication barriers contribute to increased vulnerability in an emergency situation and present unique considerations for emergency responders [6-8]. Members of the Deaf community do not see themselves as disabled but rather as members of a linguistic minority group centered on the use of sign language, which must be taken into account when designing training programs for both emergency responders and to enhance preparedness efforts by community-based organizations (CBOs) serving the Deaf community. Cultural competence is an important consideration. It is defined by the Office of Minority Health's National Standards for Culturally and Linguistically Appropriate Services (CLAS) in Health Care as "a set of congruent behaviors, attitudes, and policies that come together in a system, agency, or among professionals that enables effective work in crosscultural situations [9]."

\section{Rationale for evaluation research}

There is relatively little research or evaluation on the efficacy of preparedness efforts, particularly for those with disabilities. Given the relatively few Deaf/HH specific training programs available and the lack of evaluation of such programs, there is a need to develop best practices for emergency preparedness training for four audiences: 1) state-level emergency management and public health agencies; 2) local emergency responders; 3) Deaf-serving CBOs; and 4) Deaf community members. To date, there have been no published evaluations of trainings for emergency responders or trainings that target Deaf/HH people. In 2011, a pilot mixed methods evaluation was conducted of a training workshop for law enforcement as emergency responders for the purpose of increasing officers' cultural competency in working with Deaf and hard-of-hearing people (Deaf/HH) during domestic and sexual violence (DV/SV) emergencies [2].

\section{History of emergency preparedness training}

To date, we have identified only fifteen training programs and disaster simulation exercises for the Deaf/ $\mathrm{HH}$ across the country targeting emergency responders (5), certified ASL interpreters (2), deaf-blind people (1), government agencies (4) and the Deaf community (7). Some training programs target multiple audiences. These training programs range from onetime workshops to more extensive training modules (Table 1).

These types of targeted training efforts for the Deaf/ $\mathrm{HH}$ began for the first time during the decade post-9/ 11 [22]. For example, in 2006, the Helen Keller National Center provided a training workshop on emergency and disaster preparation for deaf-blind people. The 12-hour multi-session curriculum focused on: disasters that affect different areas of the country; how to set up a personal support network; emergency bag and disaster kit preparation; possibilities to consider in an evacuation situation; communication with emergency responders; use of personal and emergency alert systems; rental and homeowner's insurance; and different aspects of water and food safety [23].

In addition, in 2010, the first training of its kind in the country began for certified ASL interpreters to work as emergency responders through a partnership between California Emergency Management Agency (CalEMA) and NorCal Center on Deafness [21,24]. Three courses were offered for approximately 100 Certified ASL interpreters. According to Jordan Scott at CalEMA, when the program was being developed: "it was determined that, because of the chaotic nature of disasters, and the need for accurate and timely communication to the public in a shelter environment or during a press conference, it was important that prerequisites for the participants be established. In order to be eligible for Cal EMA's program, the interpreter must possess a valid certification (CDI; NAD Level 3, 4 or 5; RID CI/CT; NIC Generalist, Advanced or Master Level.) In addition they must have a minimum of 10 years of community sign language interpreting experience, with 5 years of medical, law enforcement or mental health emergency interpreting experience" (Scott J, California Emergency Management Agency, Personal Communication, January 1, 2012). There has not been an opportunity to actually deploy any interpreters during a disaster and Cal EMA is in the process of developing an on-line refresher course so the interpreters can renew their credential status in preparation for future disasters. In general, the scope of these twelve trainings varies considerably according to target 
Table 1 Existing deaf preparedness training workshops and disaster simulation exercises*

\begin{tabular}{ll}
\hline $\begin{array}{l}\text { Target } \\
\text { audience }\end{array}$ & Location served \\
\hline $\begin{array}{l}\text { First Responders } \\
\text { First }\end{array}$ & Faribault, MN \\
Responders & \\
$\begin{array}{l}\text { First } \\
\text { Responders }\end{array}$ & Riverside, CA \\
First & Gallaudet University, \\
Responders & Washington, DC \\
First & Lancaster, PA \\
Responders & \\
First & Nationally \\
Responders &
\end{tabular}

\section{Federal/state/local agencies}

$\begin{array}{lll}\begin{array}{l}\text { Law } \\ \text { Enforcement }\end{array} & \text { Statewide, IL } & \text { Illinois State Police Department [15] } \\ \begin{array}{l}\text { Emergency } \\ \text { preparedness } \\ \text { officials }\end{array} & \text { Springfield, IL } & \text { Illinois Department of Health [16] } \\ \begin{array}{l}\text { Homeland } \\ \text { Security } \\ \text { Officials }\end{array} & \text { Nationally } & \text { CEPIN [14] } \\ \begin{array}{l}\text { Law } \\ \text { enforcement }\end{array} & \text { San Francisco Bay Area, CA } & \begin{array}{l}\text { DeafHope, in partnership with Oakland Police } \\ \text { Department [2] }\end{array}\end{array}$

Faribault Disaster Exercise [10] Disaster simulation video

Riverside Disaster Exercise, California School for the Disaster simulation video Deaf at Riverside [1 1]

CERT (Community Emergency Response Team), Serve One-time, three hour workshop (July 10-12, DC--the Mayor's Office of Volunteerism [12] 2012)

Lancaster Volunteer Ambulance Corps [13]

CEPIN (Community Emergency Preparedness Information Network) [14]

Teaching emergency sign language and installing sign language apps for EMS

Training module and internet-based training in selected major cities

Module placed in Illinois state police cruisers about cadet training processes.

One time conference workshop on collaborating with the Deaf/HH

Training module and internet-based training selected major cities

One-time continuing education workshop on working with the Deaf/HH in domestic violence emergencies

\section{Deaf/HH community}

\begin{tabular}{|c|c|}
\hline $\begin{array}{l}\text { Deaf } \\
\text { community }\end{array}$ & $\begin{array}{l}\text { Northern California (Sant } \\
\text { Rosa, CA) }\end{array}$ \\
\hline $\begin{array}{l}\text { Deaf } \\
\text { community }\end{array}$ & $\begin{array}{l}\text { Gallaudet University, } \\
\text { Washington, DC }\end{array}$ \\
\hline $\begin{array}{l}\text { Deaf } \\
\text { community }\end{array}$ & Rochester, NY \\
\hline $\begin{array}{l}\text { Deaf } \\
\text { community }\end{array}$ & Nashville, TN \\
\hline $\begin{array}{l}\text { Deaf } \\
\text { community }\end{array}$ & Faribault, MN \\
\hline $\begin{array}{l}\text { Deaf } \\
\text { community }\end{array}$ & Riverside, CA \\
\hline $\begin{array}{l}\text { Deaf } \\
\text { community }\end{array}$ & Nationally \\
\hline $\begin{array}{l}\text { Deaf-blind } \\
\text { individuals }\end{array}$ & New York, NY \\
\hline \multicolumn{2}{|c|}{ ASL interpreters } \\
\hline $\begin{array}{l}\text { ASL } \\
\text { interpreters }\end{array}$ & $\begin{array}{l}\text { Northern California (San } \\
\text { Francisco Bay Area, } \\
\text { Sacramento, CA) }\end{array}$ \\
\hline $\begin{array}{l}\text { Certified ASL } \\
\text { interpreters }\end{array}$ & $\begin{array}{l}\text { Northern California (San } \\
\text { Francisco Bay Area, } \\
\text { Sacramento, CA) }\end{array}$ \\
\hline
\end{tabular}

COPE (Citizens to Prepare for Emergencies) and Sign One time workshop Language People [17]

CERT (Community Emergency Response Team), Serve DC--the Mayor's Office of Volunteerism [12]

Red Cross Greater Rochester Chapter [18]

Hearing Bridges partnered with the Nashville Area Chapter of the American Red Cross and National Weather Service [19]

Faribault Disaster Exercise [10]

Riverside Disaster Exercise, California School for the Deaf at Riverside [11]

CEPIN [14]

Helen Keller National Center [20]

One-time, three hour CERT workshop (July 1012, 2012)

Safety training workshop in CPR and first aid

One-time SKYWARN Storm Spotter training on preparation for weather emergencies

Disaster simulation video

Disaster simulation video

Training module and internet-based training in selected major cities, including fire prevention and safety

12-hour curriculum

NorCal Center on Deafness, CalEMA [21]

NorCal Center on Deafness, CalEMA [21]
FAST training: Functional Assessment Shelter Team

Disaster Relief Interpreting Program 
audience and geographic location. While the effectiveness and impact of these trainings still need to be evaluated, save one, the variance between them demonstrates a need for more standardization on a national level.

\section{Methods}

We conducted a literature review, a state agency-level assessment of trainings for the Deaf/HH, a local assessment of $\mathrm{CBO}$ capacity, as well as a first-responder training evaluation. All interviews were conducted by trained interviewers. Informed consent was obtained from all participants for publication of this report and any accompanying images.

\section{Literature review}

Inclusion criteria for the literature search in peer-reviewed databases included all literature or reports from the United States in English, 1990-2012. The peer-reviewed literature was searched using PubMed and Google Scholar, and grey literature on training evaluation was searched using Google, as well as by examining Community Emergency Response Team (CERT) newsletters. The following search terms were used: "Deaf CERT training," "Deaf emergency training," "Deaf disaster training," and "Deaf hurricane training," "Deaf earthquake," "Deaf flood," "Deaf fire," and "Deaf all-hazards."

\section{State-level agency training needs assessment}

University of California, Berkeley (UCB) researchers interviewed key informants (KIs) from state and territorial level emergency management or public health agencies in order to assess emergency preparedness information and capacity to respond to the Deaf/HH during an emergency. Fifty-nine KIs (all US states, DC, and territories) were sampled, $50 \mathrm{KI}$ telephone interviews were completed and 55 basic State Emergency Operation Plans (EOPs) were obtained and analyzed from agencies. The Office of Public Health Preparedness and Response (OPHPR) Extramural Research Program Offices (ERPO) and the Division of State and Local Readiness (DSLR) assisted in identifying contacts to help us obtain EOPs. State-level participants were assured of full confidentiality of their information prior to participation. For the purposes of this paper, we report analysis of three training-related interview items about departmental or other trainings attended by the KI interviewees. Other manuscripts available and in preparation will review results from remaining survey items asked of state personnel [25].

\section{Local-level training needs assessment Sampling frame}

A sample of 14 deaf-serving CBOs were selected for KI interviews based on expert opinion from the head of a deaf-serving organization in the San Francisco Bay Area in consultation with the project's National Advisory Board (NAB) of leaders from the Deaf/HH community, a deaf graduate student researcher, and a project consultant with certification in ASL interpreting and expert knowledge of the Deaf community in Northern California. These 14 deaf-serving CBOs have on average 5,970 clients (median: 475; range: 75-60,000 clients) and of the clients served, $20-100 \%$ are Deaf or $\mathrm{HH}$. For the purposes of this paper, analysis is reported for trainingrelated survey questions only. Questions included emergency preparedness education for clients and staff, as well as client characteristics, $\mathrm{CBO}$ capacity to reach their constituents in an emergency, barriers and supports for the development and dissemination of preparedness materials, and partnerships with other organizations. Participants were assured of full confidentiality of their information prior to participating.

\section{Instrument}

We developed a semi-structured interview guide in written English for nine Deaf/HH KIs and translated the guide into ASL Gloss (a written format that approximates ASL grammar, morphology, prosody, and syntax) for five Deaf/HH KIs. A similar interview guide for Deaf women by Steinberg et al. (2002) also used ASL Gloss and defines it as standard written format used to represent ASL [26]. Before the interview, all KIs were asked how they preferred to communicate, whether it should be in spoken English, Signed Exact English (SEE), or ASL. An ASL Gloss was created for the interview guide in order to ensure that every KI interview was administered by the interviewers in a consistent format, whether in spoken English or in ASL. The ASL Gloss, developed by a Deaf graduate student researcher in conjunction with a certified ASL interpreter, was created to ensure that the instrument was linguistically and culturally appropriate.

\section{Local Law enforcement training evaluation}

We also conducted an evaluation of a law enforcement training in Oakland, CA, to promote better response to domestic violence emergencies involving the Deaf/HH. Participants in the workshop included police officers and other law enforcement personnel, including police dispatchers. Data were collected through (1) a pre- and post-test survey [ $\mathrm{n}=34]$ administered immediately before and after the training, and (2) two semi-structured focus groups [ $\mathrm{n}=6$ and $\mathrm{n}=13$ ] with the same participants. Focus group activities occurred on the same day after two 2-hour educational outreach/training certification workshops for law enforcement personnel in the San Francisco Bay Area [2]. A trained focus group facilitator conducted the focus group. Survey items included a 
measurement of attitudes, including perceived capabilities of Deaf people, with six items such as "Deaf people can make their own life decisions" and "Deaf people can have normal one-on-one interactions on a daily basis," and perceived self-efficacy when working with the Deaf/ $\mathrm{HH}$, with ten items such as "I feel confident I could figure out a way to communicate with Deaf people in an emergency." Due to the dearth of instruments on Deaf preparedness, survey items were adapted from several extant instruments [27-32].

\section{Analytical methods}

For all of these research activities, close-ended items were entered and analyzed in SPSS. We developed descriptive statistics and conducted bivariate analysis. For openended items, we applied qualitative coding and content analysis in Excel for identifying themes across state respondents or CBOs that were reported for contextual understanding.

\section{Results}

The key findings include (1) a major gap in the literature related to Deaf/HH emergency preparedness, (2) evidence that the staff at state and territorial level agencies do not receive adequate cultural competency training in serving the Deaf/HH during emergencies, (3) evidence that only about $1 / 3$ of Deaf-serving CBOs attended emergency preparedness training, only about $1 / 2$ provided trainings to clients, and fewer than $1 / 2$ provide preparedness education materials to clients, and (4) evidence that trainees who attended a local law enforcement training on serving the Deaf community demonstrated greater perceived self-efficacy when working with the Deaf and greater knowledge of communication and translation needs for interacting with Deaf/HH individuals following the training.

\section{Literature review}

There is almost no literature about broader emergency preparedness communication issues for and by the Deaf/ $\mathrm{HH}$ across various domains [2]. We could find no peerreviewed literature specifically on emergency preparedness training and evaluation for the Deaf/HH. Zero peerreviewed articles were found using databases including PubMed and Google Scholar.

In the "grey" unpublished literature, we were able to find and review only two documents through a Google search. They included the U.S. Fire Administration's (2002) tip sheet for assisting Deaf/HH individuals in the event of an evacuation, and the U.S. Department of Justice's (2009) report entitled "Victims with Disabilities: Collaborative, Multidisciplinary First Response Techniques for First Responders Called to Help Crime Victims Who Have Disabilities Trainer's Guide" [33,34]. The information in these documents aimed to help first responders communicate with the Deaf/HH in an emergency. We found no other grey literature that addressed emergency preparedness training for the Deaf/HH.

\section{State-level agency training needs assessment}

Results indicated a significant association between a statelevel KI's familiarity with communication issues faced by the Deaf/HH and: 1) whether or not the KI's department provides any trainings to him/her or other staff regarding how to serve the Deaf/HH populations during emergencies or disasters $(\mathrm{p}=0.02)$; and 2 ) whether or not the KI or other staff have attended any other trainings outside of their departments on serving the Deaf/HH populations during emergencies or disasters $(\mathrm{p}=0.02)$.

In addition, there was a significant association between a KI's familiarity with how to make and accept relay phone calls (a critical mechanism for 2-way communication with Deaf/HH individuals during an emergency) and: 1) whether or not the KI's department provides any trainings to him/her or other staff regarding how to serve the Deaf/HH populations during emergencies or disasters $(\mathrm{p}=0.008)$; or 2 ) whether or not the KI or other staff have attended any other trainings outside their department on serving the Deaf/HH populations during emergencies or disasters $(\mathrm{p}=0.004)$.

Approximately half of state KIs reported that their own department had not provided any training, however $67.3 \%(n=33)$ had attended other trainings outside of their departments on serving the Deaf population during emergencies (Tables 2 and 3).

\section{CBO data analysis}

According to $14 \mathrm{KI}$ interviews at local deaf-serving CBO's in SF Bay Area, only 36.4\% of CBOs provided specific information on emergency preparedness to their clients and only $35.7 \%$ had attended trainings about serving Deaf/HH populations during emergencies or disasters at other organizations. Additionally, only half (50\%) of the CBO's provided classes or trainings about emergency preparedness to clients or caregivers, and only $43 \%$ provided emergency preparedness educational materials to clients [35] (Figure 1).

Despite the fact that $50 \%$ of the deaf-serving organizations reported providing medical services, chronic disease management, and skilled nursing, only $14.3 \%$ reported providing emergency preparedness services. Therefore, in addition to a lack of training, Deaf/HH clients from these organizations are underserved in terms of emergency preparedness, evacuation services in a disaster response phase, and recovery assistance following an event. Only $21.4 \%$ of CBOs provided evacuation services and only $14.3 \%$ provided recovery assistance to their clients [36]. In addition, despite the fact that deaf-serving organizations 
Table 2 State-level Deaf/HH trainings provided

\begin{tabular}{lcc}
\hline Question & YES & NO \\
\hline $\begin{array}{lc}\text { Does your department provide any training to you or other staff regarding how to serve the Deaf and Hard of Hearing } \\
\text { populations during emergencies or disasters? }(\boldsymbol{N}=50)\end{array}$ & $52 \%$ & $48 \%$ \\
$(\mathrm{~N}=26)$ & $(\mathrm{N}=24)$ \\
$\begin{array}{l}\text { Have you or other staff attended any other trainings on serving the Deaf and Hard of Hearing populations during } \\
\text { emergencies or disasters? }(\boldsymbol{N}=49)\end{array}$ & $67 \%$ & $24 \%$ \\
\hline
\end{tabular}

are expected to be uniquely attuned to the literacy and functional needs of their respective constituents, written emergency preparedness materials designed for dissemination to Deaf audiences appear to be lacking. The readability of $100 \%(5 / 5)$ of the sample of materials collected from deaf-serving CBO's tested above the average literacy level for Deaf/HH populations [25].

On average, KIs from deaf-serving CBOs reported a median of 12 months since attending specific training on emergency preparedness (range: 1-72 months ago). In terms of frequency of attendance, $28.6 \%$ of respondents said it was a one-time training, $28.6 \%$ said it was an annual training, and $42.9 \%$ said they attended training at some other interval (Table 4). In addition, KIs from deaf-serving $\mathrm{CBOs}$ had various levels of familiarity with communication issues facing their constituents in an emergency (Figure 2).

Half of the KIs (50\%) in deaf/HH-serving CBOs reported that the $\mathrm{CBO}$ provided any classes or training for clients or caregivers about emergency preparedness Figure 1. However, only a little over a third of the KIs (36.4\%) reported that the $\mathrm{CBO}$ provided training specific to the issues that Deaf/HH people face in an emergency (Table 4).

\section{Evaluation of local law enforcement training}

Results from both the survey $(\mathrm{N}=34)$ and two focus groups (total $\mathrm{N}=19$ ) demonstrated that participants gained cultural competency skills post-training as indicated by items measuring attitudes towards the Deaf/HH, perceived better self-efficacy when working with the Deaf/ $\mathrm{HH}$ both in a DV emergency and in a large-scale emergency, as well as by demonstrating knowledge of communication and translation needs for interacting with Deaf/

Table 3 Frequency of Deaf/HH training attendance by state agencies

\begin{tabular}{|c|c|c|}
\hline Frequency of training & Percentage (\%) & Responses $(N=32)$ \\
\hline Annual & 37.5 & 12 \\
\hline One time training & 37.5 & 12 \\
\hline Attend every so often & 9.4 & 3 \\
\hline As requested & 6.2 & 2 \\
\hline Other ${ }^{*}$ & 9.4 & 3 \\
\hline TOTAL & 100 & 32 \\
\hline
\end{tabular}

*Includes: Training currently not available, frequency depends on funding, and does not know frequency.
$\mathrm{HH}$ individuals during emergencies. The attitudes subscale of the survey showed that the training had a positive impact on general attitudes towards the Deaf/HH, including perceived self-efficacy when working with the Deaf/ $\mathrm{HH}(\mathrm{t}(33)=-5.02, \mathrm{p}<0.01)$, which, in this case, is partly a reflection of cultural competence, but not on their perception of the capabilities of the Deaf $/ H H(\mathrm{t}(33)=-0.34$, $\mathrm{p}=0.74)$.

However, survey participants demonstrated a lack of knowledge about federal and state-level policy and the law, which can have serious implications at the time of an emergency. For example, emergency responders encountering a Deaf/HH person at the time of an emergency may not consider securing an American Sign Language interpreter, which is required by law. Post-training, few participants were able to mention the two federal laws which protect the rights of Deaf Americans by name: The Americans with Disabilities Act (ADA) and Section 504 of the Rehabilitation Act of 1973 [2].

\section{Discussion}

In this study, data from multiple sources: a literature review, State $\mathrm{KI}$ interviews, deaf-serving $\mathrm{CBO}$ KI interviews, and the training evaluation with first responders, all showed a critical lack of training about Deaf/HH emergency preparedness for Deaf/HH clients, CBOs, and emergency responders. Given the lack of evaluation of these types of trainings in the literature, a much more rigorous approach to assessing efficacy of the trainings is needed. The literature review indicates that there is a critical need for evaluation of trainings specific to Deaf/HH individuals in order to ensure effective training procedures and emergency preparedness programs for these populations. We also need further research on factors that promote or

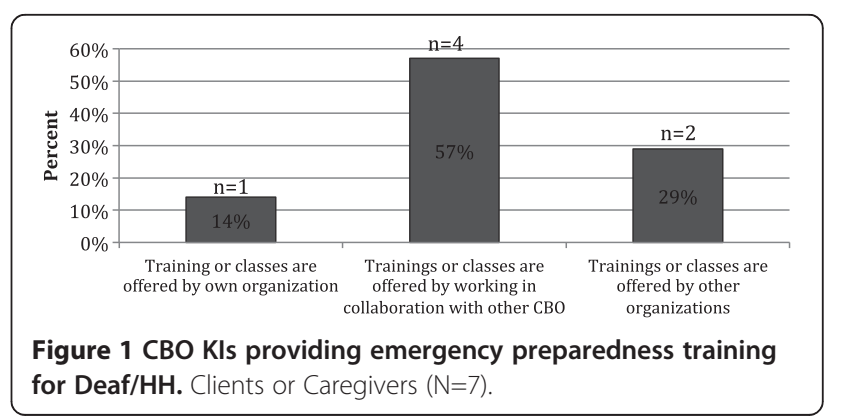




\begin{tabular}{lc}
\hline & $\begin{array}{c}\text { Deaf/HH-serving organizations } \\
\text { percentage (\%) }\end{array}$ \\
\hline Provide training to you or other staff about emergency preparedness $(\mathrm{N}=14)$ & 78.6 \\
Provide specific information on emergency preparedness for (older adult/Deaf/HH) populations $(\mathrm{N}=11)$ & 36.4 \\
You or staff have attended other training about serving (older adult/Deaf/HH) populations during & 35.7 \\
emergencies or disasters $(\mathrm{N}=14)$ & \\
\hline
\end{tabular}

hinder preparedness communication capacity of agencies that serve Deaf/HH populations in disasters, deaf/HHserving CBOs, and Deaf/HH individuals [2,25].

On a system-wide level, little information exists about national/state guidelines for emergency communication for Deaf/HH groups. However, according to FEMA's recent conference on Promising Practices in Inclusive Emergency Management (2011), one promising practice for training state emergency management personnel can be found in Hawaii, where people with disabilities are training emergency responders [5].

\section{State Kls}

Despite the lack of training described by state officials interviewed, several of them brainstormed solutions and cited barriers such as cultural issues, identifying the Deaf before and during emergencies, including Deaf/HH individuals in mass notification systems, and tailoring messages to this population. They also identified systemic challenges such as a lack of training about these issues, lack of accessible infrastructure, a need for more compliance with existing legislation for mass communication, and the need for improved collaboration and partnerships with local and state-level deaf-serving organizations.

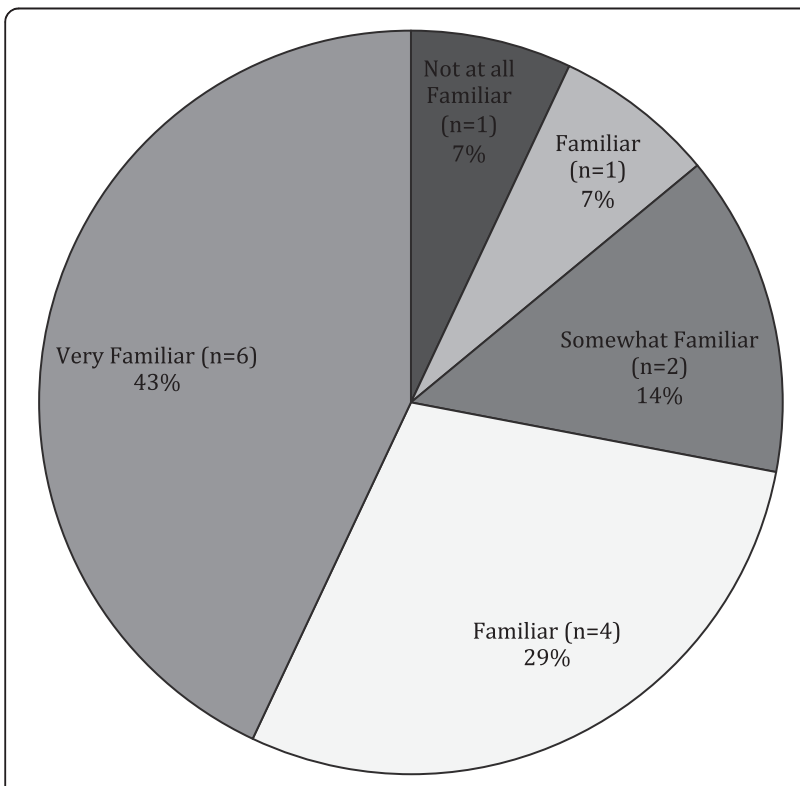

Figure 2 Deaf/HH-serving CBO familiarity with communication issues $(\mathrm{N}=14)$.
Despite the lack of training noted by state officials, several respondents discussed technological initiatives to improve access for the Deaf/HH. One respondent, referring to a question about state-level strategies for improving emergency communication for the Deaf/HH, discussed a initiative to implement a new (State) Alert and Warning System with pilot tests in two counties in which people would register their information into the system and choose how they would like to be contacted in the event of an emergency.

\section{Deaf-serving CBOs}

Fourteen CBOs reported serving Deaf/HH clients who are minority, low-income, limited English proficiency, and low-literacy. In addition, most respondents reported serving clients who are homeless, homebound, or have limited or no transportation. These demographics indicate that training is especially important for these organizations because deaf-serving CBOs are working with individuals who have multiple risk factors before and during a disaster that may impact their safety more than many other individuals and these $\mathrm{CBOs}$ may have unique access to these individuals. In addition, training for deaf-serving $\mathrm{CBOs}$ is much needed due to the fact that these CBOs are non-profit organizations operating on very limited budgets. Especially in this economic climate, CBOs often lack resources for capacity building, which is problematic in light of the fact that Deaf/HH communities depend on local CBOs in the event of a disaster.

\section{Policy implications}

Significant gaps in emergency preparedness training for serving the Deaf/HH exist despite the fact that in 2011 President Obama recommitted to enforcing and protecting the civil rights of people with disabilities on the 21st anniversary of the Americans with Disabilities Act (1990): "The promise of the ADA was that all Americans should have equal access and equal opportunity, including Americans with disabilities. The ADA was about independence and the freedom to make of our lives what we will. We celebrate that today, and we recommit ourselves to ending discrimination in all its forms," said President Obama [37].

This current research, coupled with more stringent enforcement of existing federal legislation, provides the kind of data and guidance that can impact national policy regarding the implementation of emergency response 
and planning tools that are tailor-made for the Deaf and hard-of-hearing.

The timing of this research is fortuitous. Over a decade of research indicates that input from the Deaf/HH community and from people with disabilities is increasingly being acknowledged as important and actionable, both within the research community and also in emergency management. Recent trends in emergency management include incorporating a whole community planning approach, which is defined by Kailes (2011) as an emerging community-oriented approach to models for practice of emergency management, and that recognizes:

". . . in large scale disasters, the needs of survivors outweigh collective resources and capabilities of government ... it really looks beyond traditional governments approach and all thinking government can solve disaster management challenges on its own. And it's really acknowledging that even small and medium sized events can be helped when government expands its reach and delivers services more efficiently by partnering with the community [38]. "

Acknowledging resource limitations in a large-scale disaster, whole community planning approaches involve: 1) non-governmental organizations, 2) businesses, and 3) government [39].

The more prepared emergency responders are in meeting the needs of Deaf/HH individuals in emergencies, the better prepared they will be in serving other vulnerable populations such as linguistic minorities. Lessons learned by addressing communication barriers faced by the Deaf/ $\mathrm{HH}$ can be applied to 120 million Americans who also face communication barriers: low health-literate members of society (90 million) and linguistic minorities (30 million) $[39,40]$. Targeted preparedness training materials can be disseminated to community-based organizations, communication strategies can be targeted for unique needs of diverse communities, and training can increase the capacity of both organizations and individuals to help serve the overwhelming needs seen in many recent disasters, potentially increasing resilience in diverse communities.

\section{Limitations}

Limitations of the study include the small sample size inherent in US state-level analysis, the small number of Deaf-serving CBOs in our sample, and the single evaluation of a training program. However, there are only 50 states, $1 \mathrm{DC}$, and 8 territories, so this limitation is common to all state-level analysis. In addition given that deafness is a relatively low incidence disability, there is a small universe of Deaf-serving CBOs from which to choose. For the evaluation study, only one of the instruments that we adapted for use was peer reviewed due to the fact that there was a lack of available instruments. Our instruments were also newly created and pilottested with experts in, and affiliated with, the Deaf community and were created out of necessity because there were none available. Future researchers could attempt to replicate findings. Findings may have applicability to other populations with communication barriers such as limited-English proficiency populations.

\section{Conclusion}

\section{Future directions}

Our research indicates the need for: 1 ) increased accessibility and involvement of the Deaf/ $\mathrm{HH}$ in training and exercises with guidance from state personnel; 2) required cultural competence training for first responders in order for them to better understand the diversity within this population (Deaf/deaf-blind/hard-of-hearing/late deafened) and improved emergency responder communication approaches; 3) standardized guidelines for $\mathrm{CBOs}$ to participate in local emergency and preparedness planning and exercises as fully as possible; and 4) development and dissemination of national guidelines about functional and access needs specific to the Deaf/HH population to emergency preparedness and response trainers across the nation [37]. Establishing a national taskforce is a critical first step in the development of appropriate guidelines.

Since 9/11, important first steps have been taken to train emergency responders, Deaf/HH individuals, and sign-language interpreters to prepare for emergencies or disasters. However despite the limitations of our predominantly qualitative study, our research indicates that trainings specific for Deaf/HH are rare, even for state agency personnel, frequently lack standardization or evaluation, have not been institutionalized in the emergency management infrastructure, and thus there is no consistent curriculum across agencies. Programs on which we found information had few quality control or quality improvement measures and demonstrate a lack of coordination of efforts across agencies and organizations which are providing the trainings. On a policy level, there needs to be more mainstreaming of the needs of the Deaf/HH in emergency training and operations. In the long term, increasing awareness among first responders, emergency management agencies, and deaf-serving CBOs about the needs of Deaf before, during, and after disasters may lead to higher-level policy changes and improved outcomes for Deaf individuals.

Given the enormous diversity within the Deaf/HH population, developing, implementing, and evaluating emergency preparedness training cannot be achieved without forming alliances between agencies charged with emergency response and the Deaf/HH community, including getting input from experts in the emergency preparedness field who are Deaf/HH. 
Our fundamental recommendation regarding accessible emergency preparedness communication design is to ensure close participation of its intended beneficiaries as well as those involved in the communication dissemination and evaluation. All-hazards emergency preparedness communication challenges can be mitigated by a participatory design process, or a co-production of knowledge between the lived experience of Deaf/HH people, EMS system practitioners, and emergency preparedness researchers $[25,41,42]$.

\section{Abbreviations}

ADA: The Americans with Disabilities Act; ARC: American Red Cross; ASL: American Sign Language; Cal EMA: California Emergency Management Agency; CBO: Community Based Organization; CDI: Certified Deaf Interpreter; CEPIN: Community Emergency Preparedness Information Network; CERT: Community Emergency Response Team; CLAS: Culturally and Linguistically Appropriate Services; COPE: Citizens to Prepare for Emergencies; CSDR: California School for the Deaf at Riverside; DCARA: Deaf Counseling Advocacy and Referral Agency; Deaf/HH: Deaf and hard-of -hearing; DRI: Disaster Relief Interpreting; DSLR: Division of State and Local Readiness; DV: Domestic Violence; EMS: Emergency Medical Services; EOP: Emergency Operations Plan; ERPO: Extramural Research Program Offices; FAST: Functional Assessment Shelter Team; FEMA: Federal Emergency Management Agency; HRA: Health Research for Action; Kl: Key Investigator; NAB: National Advisory Board; NAD: National Association for the Deaf; NIC: National Interpreter Certification; NWS: National Weather Service; OPHPR: The Office of Public Health Preparedness and Response; PERRC: Preparedness and Emergency Response Research Center; PSE: Pidgin Signed English; RID CI/CT: Registry of Interpreters for the Deaf Certificate of Interpretation/Certificate of Transliteration; SEE: Signed Exact English; SV: Sexual Violence; UCB: University of California, Berkeley.

\section{Competing interests}

The authors declare that they have no competing interests.

\section{Authors' contributions}

$A E, S I, W T$, and $L N$ conceived the study, AE, SI, WT, LN designed the study. $A E, S I, W T$, and DD obtained, prepared, and managed the data, performed the qualitative and quantitative analyses and $\mathrm{AE}$ conducted literature review. AE wrote the initial manuscript, and SI helped to draft the manuscript. All authors interpreted the findings and approved the final manuscript.

\section{Authors' information}

Alina Engelman, DrPH, MPH, received her doctoral degree in Public Health at UC Berkeley. While completing her MPH in Global Health at Yale University, she worked in Kenya on a program evaluation of HIV/AIDS services for the deaf using community-based participatory research (CBPR) techniques. In addition to her role as a research associate on UCB PERRC's "All-Hazards Communication to Improve the Resilience of Vulnerable Populations" she was also the recipient of a Health Policy \& Health Systems Research pilot project award from the Center for Infectious Disease and Emergency Readiness at UC Berkeley.

Susan L. Ivey, MD, MHSA, is Director of Research at HRA and Associate Professor, adjunct, in the Department of Community Health and Human Development at UC Berkeley School of Public Health. Dr. Ivey is boardcertified in family medicine and practices medicine part-time with the City of Berkeley Public Health division, including on preparedness planning Winston Tseng, PhD, is Research Sociologist in the Department of Community Health and Human Development at UC Berkeley School of Public Health. He has a background in medical sociology and extensive community-based participatory research (CBPR) experience with diverse and vulnerable populations.

Donna Dahrouge, MPH, is a Research Analyst. She is the project manager for Project 1 of the Preparedness and Emergency Response Research Center (PERRC) funded by the CDC

Jim Brune, BA, is the Executive Director of Deaf Counseling Advocacy and Referral Agency (DCARA), which is a non-profit, community-based social service agency serving the Deaf community in the San Francisco Bay Area.
Linda Neuhauser, DrPH, is Clinical Professor in the Department of Community Health and Human Development at UC Berkeley and CoPrincipal Investigator of the Health Research for Action center. She focuses on research translation and has a special interest in collaborative design and evaluation of mass communication that meets people's literacy, language, cultural, disability, and other needs.

\section{Acknowledgements}

This study was supported by a Preparedness and Emergency Response Research Center (PERRC) grant from the Centers for Disease Control and Prevention, under FOA RFA-TP-08-001, to the University of California at Berkeley (grant number 5P01TP000295).

Its contents are solely the responsibility of the authors and do not necessarily represent the official views of the Centers for Disease Control \& Prevention. Special thanks to Krista Jenkins, Rossana Reis, LaRonda Zupp, Sidhanta Gurung, and Debbie Huang for their assistance on this project.

\section{Author details}

${ }^{1}$ Health Research for Action, School of Public Health, University of California, Berkeley, 2140 Shattuck Avenue, 10th Floor, Berkeley, CA 94704, USA. ${ }^{2}$ Deaf Counseling, Advocacy and Referral Agency (DCARA), 14895 East 14th Street, Suite 200, San Leandro, CA 94578-2926, USA.

Received: 8 September 2012 Accepted: 27 February 2013 Published: 7 March 2013

\section{References}

1. Stout C: "Emergency Preparedness and Emergency Communication Access: Lessons Learned Since 9/11 and Recommendations." Publisher: Deaf and Hard of Hearing Consumer Advocacy Network (DHHCAN) and Northern Virginia Resource Center for Deaf and Hard of Hearing Persons. 2004.

2. Engelman A: Addressing Disparities in Emergency Communication with the Deaf and Hard-of-Hearing: Cultural Competence and Preparedness for First Responders. Berkeley: School of Public Health, University of California, Berkeley; 2012.

3. U.S: Department of Transportation, Department of Homeland Security. Nationwide Phase 2 Report; 2006.

4. FEMA: Key Concepts for Disability Inclusive Emergency Management. 2011. http://itsallon.tv/media/slides/11-09-12-grii-sl-practices-43.txt. Accessed March 20, 2012.

5. Lin FR, Niparko JK, Ferrucci L: Hearing loss prevalence in the United States. JAMA Intern Med 2011, 171(20):1851-1853. doi:10.1001/ archinternmed.2011.506.

6. Weil E, Wachterman M, McCarthy EP, et al: Obesity among adults with disabling conditions. JAMA 2002, 288(10):1265-1268.

7. Turner O, Windfuhr K, Kapur N: Suicide in deaf populations: a literature review. Ann Gen Psychiatr 2007, 6:26.

8. Brownridge DA: Situating Research on Safety Promoting Behaviors Among Disabled and Deaf Victims of Interpersonal Violence. Violence Against Women 2009, 15(9):1075-1079.

9. Office of Minority Health: Cultural Competency Curriculum for Disaster Preparedness and Crisis Response. https://cccdpcr.thinkculturalhealth.hhs.gov/ default.asp. Accessed December 6, 2010

10. Faribault Disaster Drill Video: Community Emergency Preparedness Information Network (CEPIN). 2008.

11. Riverside County: Deaf Awareness Week video: Personal Emergency Preparedness. 2009. December.

12. Stephens K: Gallaudet University CERT Training. 2012. http://storify.com/ kim26stephens/gallaudet-university-cert-training. Accessed March 1, 2013.

13. Eaglin K: First Responders Learn Sign Language. 2012. http://www.wkbw.com/ video/First-Responders-Learn-Sign-Language-145028925.html? $\mathrm{m}=\mathrm{y} \&$ smobile=y. Accessed March 1, 2013.

14. Community Emergency Preparedness Information Network (CEPIN): Collaboration Works: Inclusion in the Disaster Preparedness Cycle Internet Training. 2010. http://www.tdiforaccess.org/CEPIN.aspx?key=CEPIN\%28About \%20CEPIN-Collaboration\%20Works\%29\&select=CEPIN. Accessed March 16, 2012.

15. Illinois State Police: Cadet Class Topic. 2012. http://www.isp.state.il.us/ academy/cadettopics.cfm. Accessed December 5, 2012. 
16. Illinois Department of Public Health: Webcast: The Deaf and Hard of Hearing Community: Services and Understanding. Paper presented at: Preparedness To Recovery; Collaborating for Resiliency. 2008.

17. DVD Release Event: Emergency Preparedness presented in ASL by Felix Macias. Santa Rosa, CA; 2010.

18. Red Cross Greater Rochester Chapter: Safety Training: ASL course offerings in Adult CPR/AED, Child and Infant CPR, First Aid, First Aid with Adult CPR/AED. 2012. http://www.urmc.rochester.edu/ncdhr/ResourceDirectory/ ListingDetails.aspx?Listing|D=69 Accessed March 1, 2013.

19. Hearing Bridges: Red Cross \& NWS Offer 1st SKYWARN Storm Spotter Class to Deaf \& Hard of Hearing Communities. 2012. http://hearingbridges.org/news/ archives/2012/03/. Accessed March 1, 2013.

20. American Foundation for the Blind: Helen Keller National Center for DeafBlind Youths and Adults. 2012. http://www.afb.org/section.aspx? Folder $\mid \mathrm{D}=3 \&$ Section $\mid \mathrm{D}=44 \& T$ Topic $\mid \mathrm{D}=252 \& D$ ocument $\mid \mathrm{D}=4469$. Accessed March 1, 2013

21. Cal Emergency Management Agency (EMA): Office for Access and Functional Needs (OAFN). http://www.calema.ca.gov/ChiefofStaff/Pages/Access-andFunctional-Needs.aspx. Accessed March 20, 2012

22. ERDHHC Video: Community Emergency Preparedness Information Network (CEPIN). 2009.

23. Chmela V: Analysis of Focus Group of Deaf-blind Individuals Concerning Emergency Alerts Prepared for Mary Watkins of WGBH-NCAM, At the Request of the American Foundation for the Blind. 2006.

24. Cal Emergency Management Agency (EMA): Guidance on Planning and Responding to the Needs of People with Access and Functional Needs. 2009. http://www.calema.ca.gov/ChiefofStaff/Pages/Guidance-On-Planning-andResponding-To-The-Needs-Of-People-With-Access-And-Functional-Needs. aspx. Accessed March 20, 2012.

25. Neuhauser L, Ivey SL, Huang D, Engelman A, Tseng W, et al: Availability and Readability of Emergency Preparedness Materials for Deaf and Hard-of-Hearing and Older Adult Populations: Issues and Assessments. PLOS ONE 2013, 8(2):e55614. doi:10.1371/journal.pone.0055614.

26. Steinberg AG, Wiggins EA, Barmada CH, et al: Deaf Women: Experiences and Perceptions of Healthcare System Access. J Womens Health 2002, 11 (8):729-741.

27. Adapted from American Association of People with Disabilities (AAPD) survey.

28. Assemi A, et al: Psychometric Analysis of a Scale Assessing Self-Efficacy for Cultural Competence in Patient Counseling. Ann Pharmacother 2006, 40(12):2130-2135.

29. The Cultural Competence and Linguistic Competence Policy Assessment (CLCPA) in developed at the request of the Bureau of Primary Health Care (BPHC) Health Resources and Services Administration (HRSA) US Department of Health and Human Services (DHHS) Question 3.

30. The Commission on Peace Officer Standards and Training, P.O.S.T: Course Evaluation Instrument. 2001

31. Goode T: Self Assessment of Cultural Competence, in Promoting Cultural Diversity and Cultural Competency Self-Assessment Checklist for Personnel Providing Services and Support to Children with Special Health Needs and Their Families, AUCD Multicultural Council and adopted from Georgetown University Child Development Center.

32. Office of Minority Health: Cultural Competence Course, Course 2: Introduction/ Pre-test, Question 8

33. Office for Victims of Crime Office, Office of Justice: Victims with Disabilities: Collaborative, Multidisciplinary First Response Techniques for First Responders Called to Help Crime Victims Who have Disabilities Trainer's Guide. Washington D.C.: U.S: Department of Justice; 2009

34. Sullivan H, Hakkinen MT: Disaster Preparedness for Vulnerable Populations: Determining Effective Strategies for Communicating Risk, Warning, and Response Paper. New Brunswick, NJ: Magrann Conference at Rutgers University; 2006.

35. Ivey S, Engleman A, Tseng W, et al: Readability Assessment of Emergency Preparedness Materials for Deaf and Hard-of-Hearing and Older Adult Populations. Anaheim, CA: Public Health Preparedness Summit; 2012.

36. Cal Prepare UC Berkeley PERRC Project Update: Paper presented at: MiniNational Advisory Board Meeting on Emergency Preparedness Communication for the Deaf and Hard of Hearing. Berkeley, CA; 2011.

37. White House Office of the Press Secretary: For the Immediate Release on the 16th Anniversary of the American with Disabilities Act. 2011

38. Kailes Jl: Emergency Registries: An Objective Analysis Tool. National Association of County and City Health Officials; 2011.
39. Kouznetsova S: Universal Accessibility Benefits Website. 2012. http://audioaccessibility.com. Accessed March 13, 2012.

40. Kutner M, Greenberg E, Baer J: National Assessment of Adult Literacy (NAAL): A First look at the Literacy of America's Adults in the 21 Century. Washington D.C: Department of Education, National Center for Education Statistics; 2005.

41. Corburn J: Community knowledge in environmental health science: coproducing policy expertise. Environ Sci Pol 2007, 10(2):150-161.

42. Neuhauser L, Rothschild B, Graham C, Ivey SL, Konishi S: Participatory Design of Mass Health Communication in Three Languages for Seniors and People With Disabilities on Medicaid. Am J Public Health 2009, 99(12):2188-2195.

doi:10.1186/1472-6963-13-84

Cite this article as: Engelman et al:: Responding to the deaf in disasters: establishing the need for systematic training for state-level emergency management agencies and community organizations. BMC Health Services Research 2013 13:84.

\section{Submit your next manuscript to BioMed Central and take full advantage of:}

- Convenient online submission

- Thorough peer review

- No space constraints or color figure charges

- Immediate publication on acceptance

- Inclusion in PubMed, CAS, Scopus and Google Scholar

- Research which is freely available for redistribution 